\title{
Development of Salt Rock Underground Gas Caverns Risk Management Information System
}

\author{
Bi He*, Baoqun Wang, Lili Tao \\ School of Civil Engineering, Shandong Jiaotong University, Jinan 250357, China \\ *hebiy@163.com
}

\begin{abstract}
Use salt rock underground caverns to store gas is an important storage mode in China, effective risk management is the key to the success of this method. Aimed to risk management, a risk management system was designed and developed, at first, overall framework of the system was designed, and then, each module was detailed designed, the risk evaluation mode was built. Application of this system can effective monitoring risk of salt rock underground gas caverns, greatly improve the level of security.
\end{abstract}

Keywords: Salt rock, Gas storage, Risk management, Information system

\section{Introduction}

In most countries, natural gas is the most important type of energy, compared with the traditional forms of energy, such as coal, natural gas has the advantages of environmental protection and high efficiency. But, the storage of natural gas is a challenging problem, in many countries, such as China, many salt rock underground caverns were used to store natural gas, and then, the risk monitor and management became one problem. Aimed to this problem, salt rock underground gas caverns risk management information system was designed and developed to improve the level of security.

\section{Overall framework of system}

The first step of designing and developing an information system is overall framework design. On the whole, salt rock underground gas caverns risk management information system was divided into three layers, the bottom layer is data layer, the center layer is business layer, and the top layer is operation layer. The structure of overall framework can be shown in figure1: 


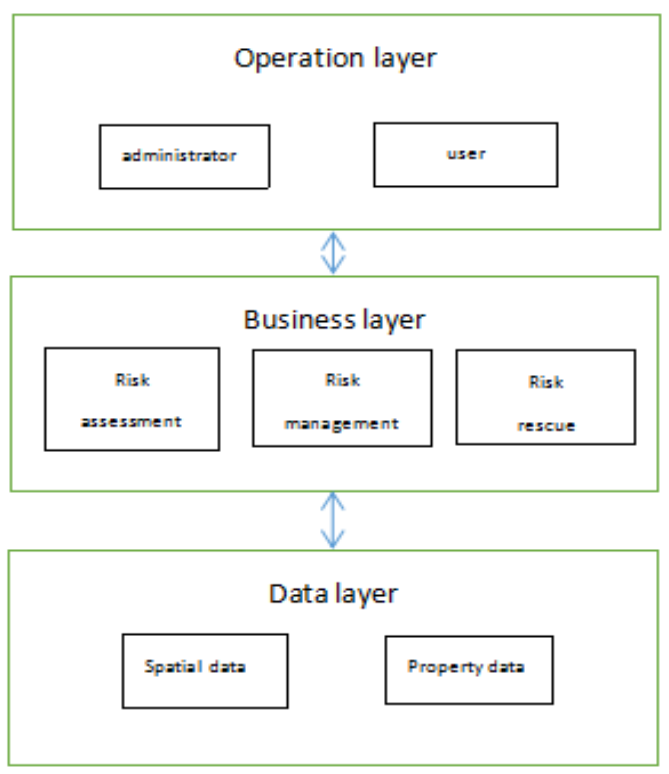

Fig.1 Overall framework of system

Data layer is foundation of whole system, its mission is input, store, manage and provide the data of whole system, the data include spatial data and property data, spatial data was used to describe position information, its main form is coordinate, and property data was used to describe characteristic or status, just like the height, width of a cavern. Data layer was built with database tool, just like Oracle, SQL Server or Access, the data from different sensors can be input data layer automatically through the program interface, the basic data can be input by manual.

Business layer is key core of whole system, its mission is complete all kinds of calculation, analyses works. It combines data, user's command requirement and analysis model to complete the corresponding task, just like risk assessment, risk management, risk rescue.

Operation layer is performance layer of whole system, and it is a interface between operator and system. Operator use the operation layer to run the system, just like input command, query information, obtain analysis results, and manage the system.

\section{Module design}

After design the overall framework of system, the every individual module should be designed. The mission of module design is detailed design how the every module can complete its function. According to the overall framework of system, we designed three main module of system: data management module, function realization module and operation interface module.

For data management module, we used GIS, GIS can manage spatial and property data at the same time. Each object, just like every part of a cavern, its spatial information, can be expressed by a set of coordinates as $(\mathrm{x}, \mathrm{y}, \mathrm{z})$, its structure can be expressed as figure2. And the property data can be stored in a two-dimensional data sheet, in the sheet, each row represents one object, and each column represents one property. The spatial and property data of one object was linked by unique symbol code. 


\begin{tabular}{|c|c|c|c|}
\hline & $C(\mathrm{X})$ & $\mathrm{C}(\mathrm{Y})$ & $\mathrm{C}(\mathrm{Z})$ \\
\hline $\mathrm{P} 1006$ & 1124.32 & 265.38 & 122.86 \\
\hline $\mathrm{P} 1007$ & $\ldots \ldots$ & $\ldots \ldots$ & $\ldots \ldots$ \\
\hline $\mathrm{P} 1008$ & $\ldots \ldots$ & $\ldots \ldots$ & $\ldots \ldots$ \\
\hline $\mathrm{P} 1009$ & $\ldots \ldots$ & $\ldots \ldots$ & $\ldots \ldots$ \\
\hline $\mathrm{P} 1010$ & $\ldots \ldots$ & $\ldots \ldots$ & $\ldots \ldots$ \\
\hline $\mathrm{P} 1011$ & $\ldots \ldots$ & $\ldots \ldots$ & $\ldots \ldots$ \\
\hline $\mathrm{P} 1012$ & $\ldots \ldots$ & $\ldots \ldots$ & $\ldots \ldots$ \\
\hline $\mathrm{P} 1013$ & $\ldots \ldots$ & $\ldots \ldots$ & $\ldots \ldots$ \\
\hline $\mathrm{P} 1014$ & $\ldots \ldots$ & $\ldots \ldots$ & $\ldots \ldots$ \\
\hline $\mathrm{P} 1015$ & $\ldots \ldots$ & $\ldots \ldots$ & $\ldots \ldots$ \\
\hline $\mathrm{P} 1016$ & $\ldots \ldots$ & $\ldots \ldots$ & $\ldots \ldots$ \\
\hline $\mathrm{P} 1017$ & $\ldots \ldots$ & $\ldots \ldots$ & $\ldots \ldots$ \\
\hline $\mathrm{P} 1018$ & $\ldots \ldots$ & $\ldots \ldots$ & $\ldots \ldots$ \\
\hline $\mathrm{P} 1019$ & $\ldots \ldots$ & $\ldots \ldots$ & $\ldots \ldots$ \\
\hline $\mathrm{P} 1020$ & $\ldots \ldots$ & $\ldots \ldots$ & $\ldots \ldots$ \\
\hline $\mathrm{P} 1021$ & 1966.62 & 598.26 & 134.77 \\
\hline
\end{tabular}

Fig.2 Coordinate value store in table

For the function realization module, we design corresponding model. Take risk assessment as an example, in its corresponding model, according to the causes of rick, the risk factors was selected at first, and then, with instrument measurement, every risk factors was assignment, after these, the model use Analytic Hierarchy Process method to quantitative calculate the rick level, and provide the results to the next model, just like assessment rescue model.

For the operation interface model, we can use Integrated Development Environment tools to develop it. Just like Visual Studio, with this develop tool, we can develop local management system interface, it runs in local computer, and we also can develop website management system interface, it runs in servers, operators can manage the system through browser, and we also can develop mobile system interface, with this interface, operators can manage the system through mobile device, like smart phone, pad, etc.

\section{Conclusion}

As an effective but risky natural gas storage method, risk management level is the key of salt rock underground caverns gas storage success or not. Develop and use of risk management information system can effectively improve the salt rock underground caverns risk management level, it is very helpful to safe storage and efficient use of energy.

\section{Reference}

[1] Ahmet Ozarsian. Large-scale hydrogen energy storage in salt caverns[J]. International Journal of Hydrogen Energy, 20127 (7) 1-3.

[2] Miguel Veiguela, Antonio Hurtado, Sonsoles Eguilior. A risk assessment tool applied to the study of shale gas resources[J]. Science of The Total Environment, 201610 (571) 551-560.

[3] M.R. Martins, M.A. Pestana, G.F.M. Souza, A.M. Schleder. Quantitative risk analysis of loading and offloading liquefied natural gas (LNG) on a floating storage and regasification unit (FSRU)[J]. Journal of Loss Prevention in the Process Industries, 20169 (43) 629-653.

[4] Yuhua Huang, Hongyu Ni. Study On Technology for CORS Service[J]. Geo-spatial Information, 2008 6(1) 34-36.

[5] Luisa Torres, Om Prakash Yadav, Eakalak Khan. A review on risk assessment techniques for hydraulic fracturing water and produced water management implemented in onshore unconventional oil and gas production[J]. Science of The Total Environment, 2016 1(539) 478-493. 
[6] ZJiyao Gao, Fengqi You. Risk Management of Shale Gas Supply Chain under Estimated Ultimate Recovery Uncertainty[J]. Computer Aided Chemical Engineering, 2016 1(38) 529-534.

[7] Shuangcheng Zhang, Haiyang Cao, Han Gao, Haiying Li. Application and analysis of GPS Short Baseline Processing Based on GAMIT[J]. Survey and Mapping Bulletin, 2011(10) 27-29.

[8] Sangick Lee, Suwon Seo, Daejun Chang. Fire risk comparison of fuel gas supply systems for LNG fuelled ships[J]. Journal of Natural Gas Science and Engineering, 2015(19) 1788-1795.

[9] Xuan Zou, Weiming Tang, Chuang Shi, Jingnan Liu. Instantaneous Ambiguity Resolution For PPP-RTK Using Regional Ground-Based Augmentation Information[J], 2014 34(1) 78-83.

[10] Xue Yang, Stein Haugen. Risk information for operational decision-making in the offshore oil and gas industry[J].Safety Science, 2016 7. 98-109. 